\title{
Ortolani Maneuver
}

National Cancer Institute

\section{Source}

National Cancer Institute. Ortolani Maneuver. NCI Thesaurus. Code C89517.

When testing for congenital dislocation of the hip, this is the result obtained when the examiner gently abducts the hip while pushing upward on the greater trochanter. If the hip is dislocated, it will relocate with an audible clunk, which is a positive result for this test. 